\title{
Minimal acupuncture is not a valid placebo control in randomised controlled trials of acupuncture: a physiologist's perspective Iréne Lund ${ }^{1}$, Jan Näslund ${ }^{1}$ and Thomas Lundeberg*2
}

\author{
Address: ${ }^{1}$ Department of Physiology and Pharmacology, Karolinska Institutet, Stockholm, Sweden and ${ }^{2}$ Foundation for Acupuncture and \\ Alternative Biological Treatment Methods, Sabbatsbergs Hospital, Stockholm, Sweden \\ Email: Iréne Lund - Irene.Lund@ki.se; Jan Näslund - Jan.E.Naslund@ki.se; Thomas Lundeberg* - thomas.lundeberg@faab.to \\ * Corresponding author
}

Published: 30 January 2009

Chinese Medicine 2009, 4:I doi:I0.I I86/1749-8546-4-I

This article is available from: http://www.cmjournal.org/content/4/I/I

(c) 2009 Lund et al; licensee BioMed Central Ltd.

This is an Open Access article distributed under the terms of the Creative Commons Attribution License (http://creativecommons.org/licenses/by/2.0), which permits unrestricted use, distribution, and reproduction in any medium, provided the original work is properly cited.
Received: 27 October 2008

Accepted: 30 January 2009

\begin{abstract}
Placebo-control of acupuncture is used to evaluate and distinguish between the specific effects and the non-specific ones. During 'true' acupuncture treatment in general, the needles are inserted into acupoints and stimulated until deqi is evoked. In contrast, during placebo acupuncture, the needles are inserted into non-acupoints and/or superficially (so-called minimal acupuncture). A sham acupuncture needle with a blunt tip may be used in placebo acupuncture. Both minimal acupuncture and the placebo acupuncture with the sham acupuncture needle touching the skin would evoke activity in cutaneous afferent nerves. This afferent nerve activity has pronounced effects on the functional connectivity in the brain resulting in a 'limbic touch response'. Clinical studies showed that both acupuncture and minimal acupuncture procedures induced significant alleviation of migraine and that both procedures were equally effective. In other conditions such as low back pain and knee osteoarthritis, acupuncture was found to be more potent than minimal acupuncture and conventional non-acupuncture treatment. It is probable that the responses to 'true' acupuncture and minimal acupuncture are dependent on the aetiology of the pain. Furthermore, patients and healthy individuals may have different responses. In this paper, we argue that minimal acupuncture is not valid as an inert placebo-control despite its conceptual brilliance.
\end{abstract}

\section{Background}

Randomised placebo-controlled clinical trials (placebocontrolled RCTs) are used to evaluate the efficacy of medical interventions. The ultimate intention of these placebo-controlled RCTs is to eliminate the non-specific placebo effects [1]. This trial design is considered as the gold standard. The results of placebo-controlled RCTs provide evidence for a treatment's efficacy [2]. However, the technical issues in developing valid placebos in acupuncture RCTs are still controversial [1,3-7].

\section{Placebo}

The placebo concept was introduced into RCTs as a treatment without curative anticipation [8]. Randomised, double-blind, placebo-controlled trials are generally considered as the best experimental method for separating the 'specific' from the 'non-specific placebo related' effects of a treatment. The placebo is supposed to be inert, inducing only non-specific physiological and emotional changes. If the intervention is a drug, the 'specific' component is the pharmacologically active agent while the placebo is an inert substance. Recent studies have, however, shown that some placebos are sometimes therapeutically effective [9]. The issue of evaluation becomes more com- 
plicated especially if the intervention in question is as complex as acupuncture $[7,10]$. Acupuncture may be viewed from a Chinese medicine perspective whereby each acupoint is associated with specific effects, or from a Western perspective whereby acupuncture is merely what its Latin name suggests - 'acus' (needle) and 'pungere' (to prick), and its effects are explained in Western physiological terms.

\section{Localisation: Chinese medicine versus physiological aspects}

In Chinese medicine, the correct acupoints are vital in the classical theory of acupuncture to achieve efficacy. A possible control intervention from this perspective is, therefore, needling at incorrect sites. From a physiological perspective, an acupoint is defined by its anatomical innervation. Needling at an incorrect site may affect the correct receptive field in terms of physiology. In such a scenario, the physiological responses to needling at incorrect sites may be identical.

\section{Needling effects: Chinese medicine versus physiological aspects}

In Chinese medicine, depths of needling, manipulation of the needle, triggering of a specific irradiating needling sensation known as deqi (considered to be associated with effective needling), duration of stimulation may all vary according to a holistic diagnosis. From a physiological perspective, acupuncture is a modality of sensory stimulation and the effects obtained are dependent on which sensory receptors are activated, the afferent activity set-up and the resulting activity in the central nervous system. The response of the nervous system to the sensory input is dependent on its present state and also on the characteristics of the individual (e.g. genotype, coping strategy, expectation and previous experiences). Given the complexity, it is not surprising that a variety of control interventions have been used in clinical acupuncture trials. Dincer and Linde reviewed the sham-controlled clinical trials of acupuncture, particularly on (a) which sham interventions were used, (b) in what respects 'true' and sham interventions differed and (c) whether trials using different types of sham yielded different results [10]. They included 47 randomised controlled trials published in English or German in which trial patients received either 'true' acupuncture or sham (referred to as 'sham' or 'placebo') for preventive, palliative or curative purposes. The sham interventions used were categorized as follows.

I: superficial needling of 'true' points (superficial needling of the acupoints for the treated condition)

II: 'irrelevant' acupoints (needling of the acupoints not for the treated condition)

III: 'non-acupuncture' points (needling non-acupoints)
IV: 'placebo needles' (devices that mimic acupuncture without skin penetration)

V: pseudo-interventions (interventions that are not 'true' acupuncture e.g. use of switched-off laser acupuncture devices)

Dincer and Linde also examined whether the 'true' and sham interventions differed in terms of points chosen, penetration of the skin, depths of needling, manipulation or stimulation of the needle, achievement of deqi, number of points, number of sessions and duration of sessions. Out of the 47 included trials, two trials employed the sham intervention that consisted of superficial needling of the 'true' acupuncture points; four trials used 'true' acupoints not indicated for the condition being treated; in 27 trials needles were inserted outside 'true' acupoints; five trials used placebo needles and nine trials used pseudointerventions such as switched-off laser acupuncture devices. 'True' and sham interventions often differed in other aspects, such as manipulation of needles, depth of insertion, and achievement of deqi and there was no clear association between the type of sham intervention used and the results of the trials. Dincer and Linde concluded that considering all these different sham interventions as simple 'placebo' controls was misleading and scientifically unacceptable [10].

\section{Effects of minimal acupuncture}

A technique defined as minimal acupuncture may be used as a control to acupuncture. The number, length, and frequency of the sessions in the minimal acupuncture are the same as for the 'true' acupuncture. Typically, at least five out of 10 predefined distant non-acupuncture bilateral points (at least 10 needles) are needled superficially in each session. Furthermore, manual stimulation of the needles and deqi is avoided. Even if this may be a valid control from the Chinese medicine perspective, it is not necessarily from a physiological perspective.

\section{Stimulus intensity}

In chronic pain patients with sensitisation of the peripheral and central nervous systems, the acupuncture stimulus response is augmented, whereby light stimulation of the skin, minimal acupuncture may have an effect as strong as acupuncture in various integrated physiological responses [11]. Central sensitisation is also associated with expanded receptive fields of central neurons, resulting in a larger topographic distribution of the pain [12]. This suggests that control procedures with light needling of the skin and/or needling away from the target treatment site (area of pain), in patients with central sensitisation, may have effects equivalent to needling within the treatment site [13]. In patients who do not suffer from central sensitisation, repeated nociceptive input from 
muscles (as obtained in deqi) results in expansion of receptive fields which may in turn lead to activation of descending pain inhibition outside the stimulated myotome [11]. In other words, a control procedure with needling in a nearby myotome may have similar effects as needling within the affected myotome. An increased sensitivity to pain, and other sensory modalities, may be related to abnormalities in descending efferent pathways and plasticity changes in the nervous system, thereby influencing the effects of acupuncture [14-16].

\section{Aetiology and characteristics of pain}

Depending on the characteristics of the pain, e.g. spontaneous, persistent or stimulus-evoked and its related default mode, acupuncture may have different effects $[11,13,17,18]$. Furthermore, the aetiology of the clinical condition or syndrome must be considered for appropriate design of the control procedure [19-23]. Otherwise, optimal pain inhibition may not be achieved [19].

\section{Physiological complexity of acupuncture effects Pain inhibition}

There are various kinds of modern and traditional approaches to acupuncture treatment $[23,24]$. Depending on the approach, different results may be obtained $[25,26]$. It has been postulated that acupuncture analgesia, in the case of manual acupuncture, is manifested by the feeling of deqi. During manual acupuncture, all types of afferent nerve fibres (A-beta, A-delta and C) can be activated while minimal acupuncture (with needles applied superficially into the skin) probably activates two types of $\mathrm{C}$ tactile fibres in the skin [27-32]. Electro-acupuncture results in activation of A-beta- and part of A-delta nerve fibres in response to the stimulating current delivered to acupuncture points via the inserted needle. The nerve impulses, emanating from the acupuncture stimulation, ascend mainly through the spinal ventrolateral funiculus to the brain. Many brain nuclei of an integrated network are involved, including the periaqueductal grey, nucleus raphe magnus, arcuate nucleus, preoptic area, locus coeruleus, accumbens nucleus, nucleus submedius, caudate nucleus, habenular nucleus, septal area and amygdale [33-37]. These areas are also involved in emotional and reward processes.

It was shown that various endogenous systems played crucial roles in acupuncture analgesia, for example, the systems that involve activation of endogenous opioids (betaendorphin, enkephalin, endomorphin and dynorphin) and the desending serotoninergic inhibitory pathway [35]. The functions of these systems altered according to the aetiology of the pain. Apart from endogenous opioids and serotonin, the cholecystokinin octapeptide (CCK-8) was shown to play a key role in the effects of acupuncture including development of tolerance [37]. The individual differences of acupuncture analgesia are also associated with inherited genetic factors and the density of CCK receptors. Furthermore, acupuncture analgesia is probably associated with its counter-regulation of spinal glial activation, PTX-sensitive Gi/o protein-mediated and MAP kinase-mediated signal pathways, and downstream processes [36].

\section{Self- appraisal}

The brain modulates processes involved in self-appraisal during acupuncture. For example, when a patient sees an acupuncturist, there is anticipation of a specific effect [3843]. This anticipation is partly based on self-relevant phenomena and self-referential introspection that will constitute the preference. These self-appraisal processes are dependent on two integrated networks, namely a ventral medial prefrontal cortex-paralimbic-limbic 'affective' pathway and a dorsal medial prefrontal cortex-corticalhippocampal 'cognitive' pathway [44].

\section{Limbic structures and reward}

The limbic structures show an increased activity in most diseases and illness responses [45-48]. Acupuncture including electro-acupuncture and minimal acupuncture may result in deactivation of limbic structures (in patients with pain) [49-53]. Deactivation of limbic structures has been associated with an increased activity in hypothalamus and the resulting activation of pain and sympathetic inhibiting mechanisms [54]. Not only does the brain modulate the activity in the hypothalamus and the limbic structures, but also modulates the reward system resulting in a sensation of wellbeing during acupuncture [44]. Acupuncture may work as behavioural conditioning, which suggests that the needling procedure per se may have therapeutic effects [55].

\section{Minimal acupuncture in migraine, low back pain and knee osteoarthritis pain}

It was suggested that both acupuncture and minimal acupuncture may induce activation of sensory afferents $[7,11,27-32]$. The relevant question is whether minimal acupuncture of the skin has a clinical effect. If it does, the present research paradigm (acupuncture versus placebo with minimal acupuncture) is not valid. This suggestion is illustrated in Figures 1, 2, 3 based on the studies of the efficacy of acupuncture in migraine (Figure 1), low back pain (Figure 2) and knee osteoarthritis pain (Figure 3) [56-66]. The results of the above studies showed that minimal acupuncture had therapeutic effects. Clinically, both 'true' acupuncture and minimal acupuncture are effective in migraine, whereas 'true' acupuncture is more effective than minimal acupuncture in low back pain and knee osteoarthritis pain [67]. 


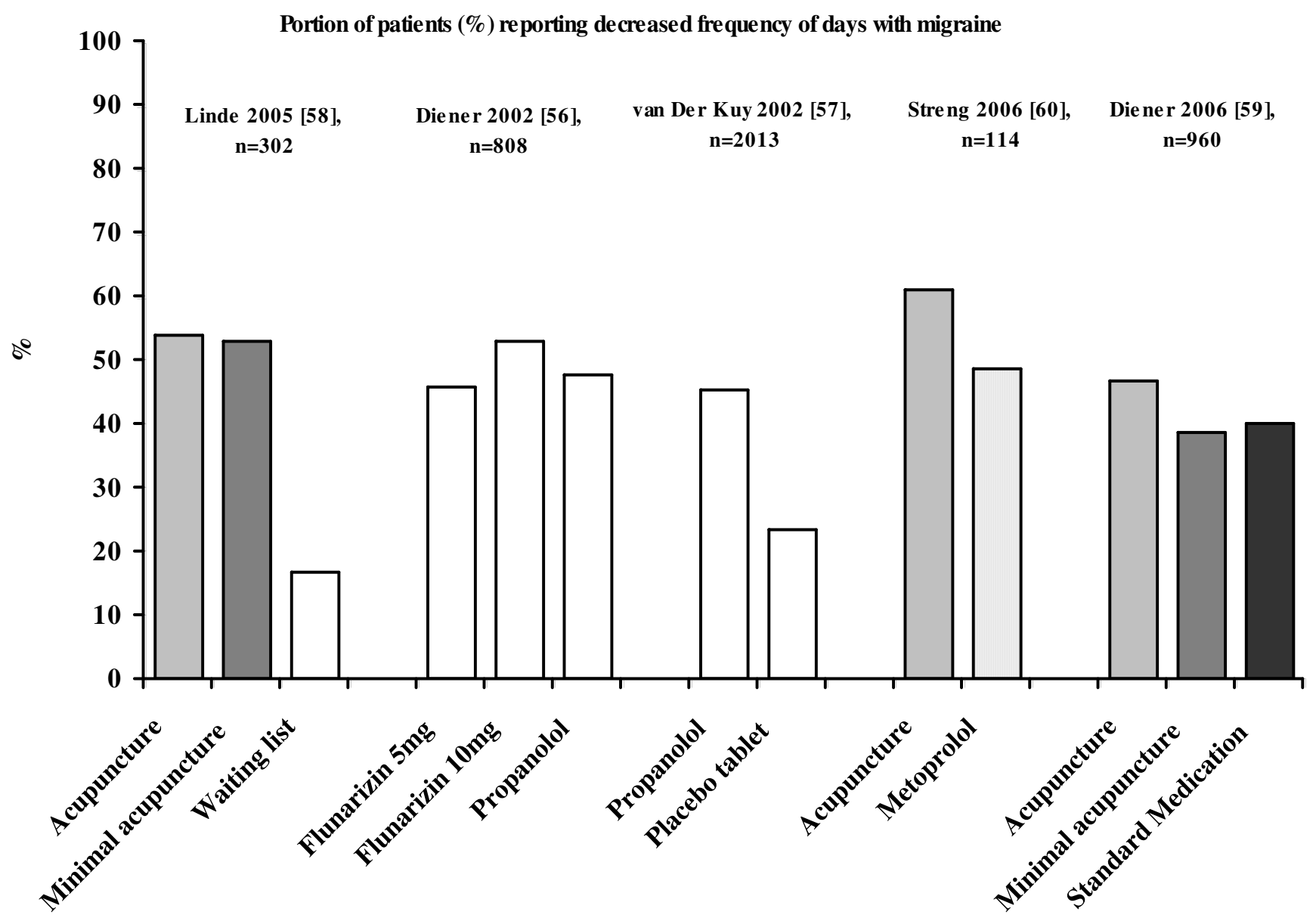

Figure I

Reported respondent rates across recent trials of migraine treated with various interventions. Respondents were defined as those who reported reduction of pain. The figure was modified from a PowerPoint presentation [6] with the permission of Dr M Cummings.

From the studies of the efficacy of acupuncture in migraine, low back pain and knee osteoarthritis pain [5566], an intriguing finding was the strong and lasting response to minimal acupuncture and the lack of significant differences between 'true' acupuncture and minimal acupuncture. This indicates that point location and other aspects considered relevant in Chinese medicine do not make a major difference. However, the improvement over, and the differences compared with, the waiting list group are clearly clinically relevant. The minimal acupuncture intervention used was, according to the investigators, designed to minimise potential physiological effects by needling superficially at points distant from acupoints as well as by using fewer needles (but still at least 10) than 'true' acupuncture. From a physiological perspective, the effects of superficial needling at the points distant from acupoints may still induce a wide range of peripheral, segmental and central physiological responses and in this respect the minimal acupuncture technique is not inert and can therefore not serve as a control for those using acupuncture in a physiological perspective (as a modality of sensory stimulation). An explanation for the improvements observed is that the effects of acupuncture and minimal acupuncture are associated with particularly potent placebo effects. Some evidence shows that complex medical interventions or medical devices have higher placebo effects than placebo drugs [4,5]. Acupuncture treatment has characteristics that are considered relevant in the context of placebo effects. It has an 'exotic' conceptual framework with an emphasis on the 'individual as a whole'. It is associated with frequent patient-practitioner contacts, and it includes the repeated 'ritual' of needling. Finally, the high expectations of patients and the way the patients were informed were demonstrated to be relevant factors in the German trials [67]. From a physiological perspective, however, these so called placebo responses of 


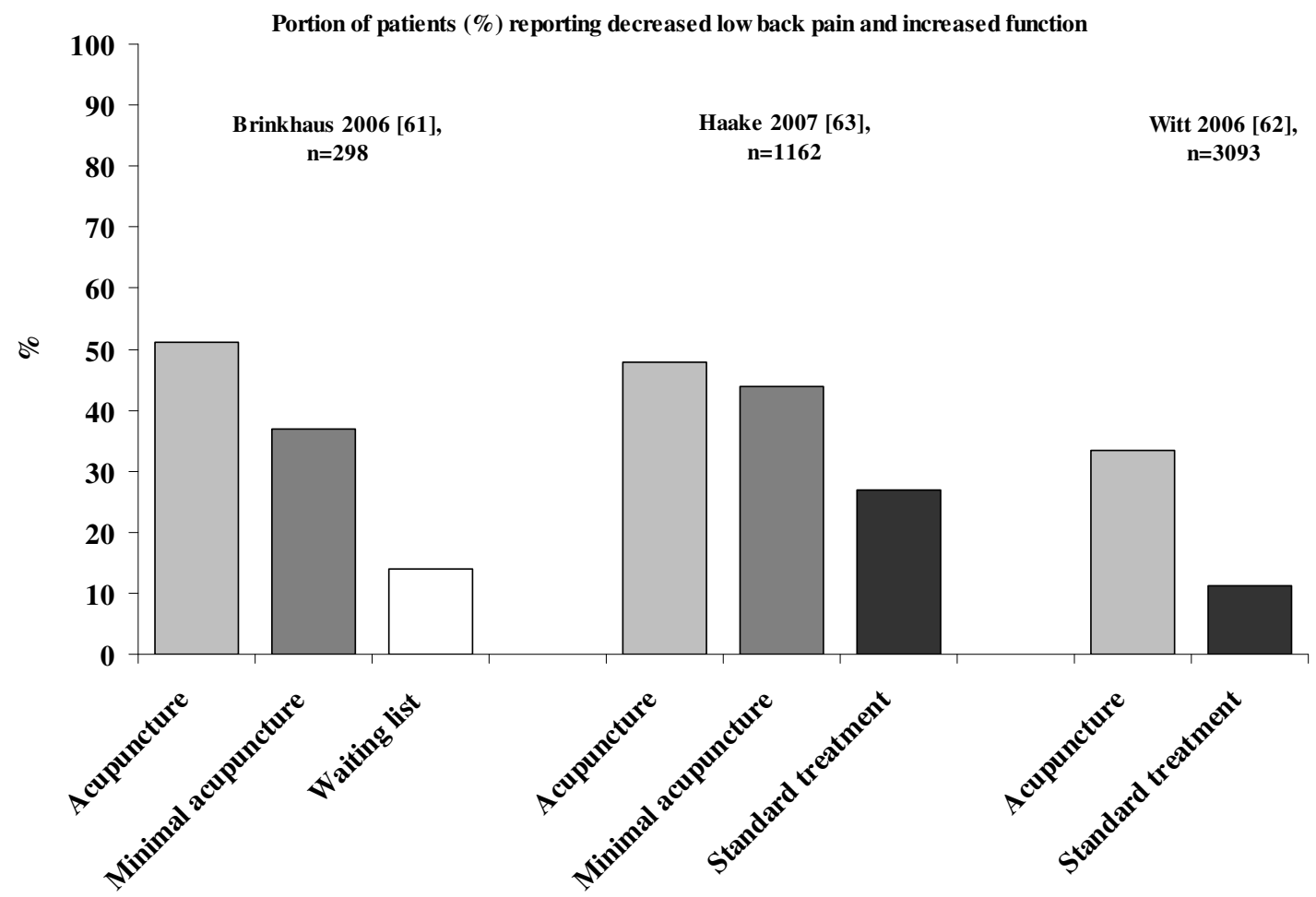

Figure 2

Reported respondent rates across recent trials of low back pain treated with various interventions. Respondents were defined as those who reported increased function. The figure was modified from a PowerPoint presentation [6] with the permission of Dr M Cummings.

the acupuncture procedure may be obtained after conditioning and Pavlovian extinction.

\section{Specific and non-specific effects of minimal acupuncture in clinical conditions - a plausible scenario}

A part of the specific effects of minimal acupuncture may be attributed to the deactivation of limbic structures and modulation of default mode $[17,68-78]$. If it is the case, needle depth or site of stimulation is not essential for eliciting some of the specific effects of acupuncture [79-84]. However, in knee osteoarthritis, minimal acupuncture did not result in the same improvement as acupuncture for the first three months. It is possible that reducing the activity in the limbic structures may restore functional connectivity, making the patient receptive to his or her expectancy of a treatment's effect (specific) and to the patient-therapist interaction (non-specific effect), i.e. the specific effects of minimal acupuncture conditions the non-specific ones [85-90]. Repeated treatment can result in Pavlovian deconditioning/extinction of, for example, knee osteoarthritis pain $[91,92]$. In such a scenario, the construction of a placebo control is virtually impossible, as any kind of sensory stimulus may have a specific effect.
Many acupuncture RCTs did not consider these aspects and therefore led to false negative results. Systematic reviews (e.g. Cochrane studies) and meta-analyses based on the RCTs with false negative results may wrongly conclude that acupuncture has no specific therapeutic effects.

\section{Other aspects of acupuncture treatment}

It is important to emphasise that acupuncture is not a simple needling intervention. There are at least three other processes, apart from needling, that characterize the acupuncture procedure, namely (1) building a treatment relationship, (2) individualizing care and (3) facilitating active engagement of patients in their own recovery [9395]. These processes include establishing rapport, facilitating communication throughout the period of care, using an interactive diagnostic process, matching treatment to the individual patient and using explanatory models to aid the development of a shared understanding of the patient's condition and to motivate lifestyle changes that reinforce the potential for a recovery of health $[96,97]$. In a sense, acupuncture requires cognitive behavioural research to further characterize its treatment process. 


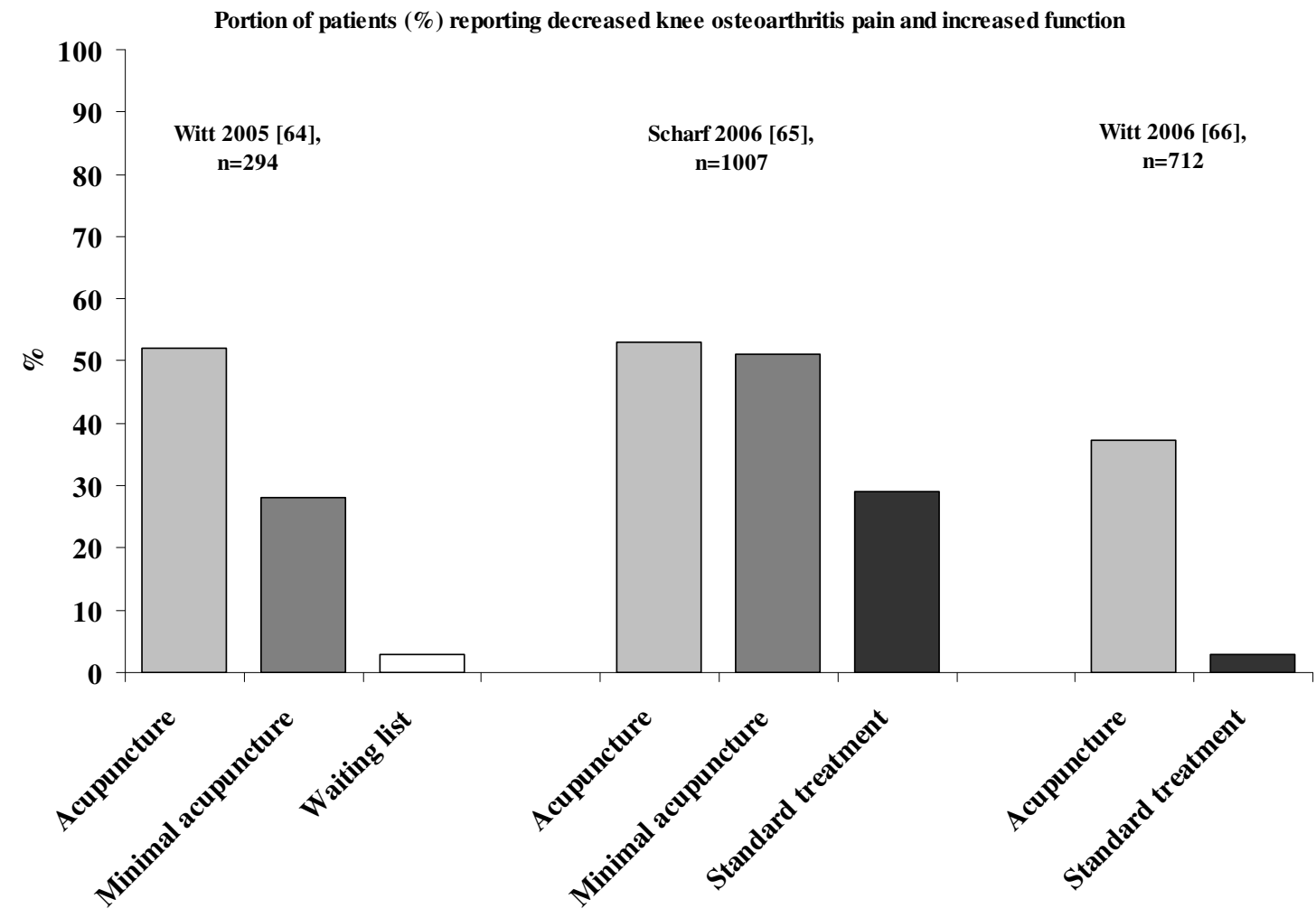

Figure 3

Reported respondent rates across recent trials of knee osteoarthritis pain treated with various interventions. Respondents were defined as those who reported increased function. The figure was modified from a PowerPoint presentation [6] with the permission of Dr M Cummings.

\section{Minimal acupuncture as a complement and the use of an observational study protocol}

In a recent study [98], researchers investigated the effectiveness of acupuncture combined with the routine medical care in patients with primary headache compared with the treatment of routine care only. Furthermore, they evaluated whether the effects of acupuncture varied in randomised and non-randomised patients. In a three-month follow-up, the number of days with headache was decreased in both acupuncture and control groups. Similarly, the decrease of pain intensity and quality of life improvements were more pronounced in the acupuncture group than that in the control group. Treatment success was maintained throughout the six-month follow-up. The outcome changes in non-randomised patients were similar to those in randomised patients. Patients in acupuncture plus routine care showed marked clinical improvements compared to those with routine care only. These results showed that acupuncture may be demonstrated as a (cost-effective) complement to routine care without using minimal acupuncture as a control. On the other hand, the use of observational study with the data carefully collected over time as events occur, as in a longitudinal study, instead of conventional RCTs, may allow a trial design that suits the clinical situation better $[99,100]$ and avoid inherent difficulties in patient information regarding the sham [101].

\section{Conclusion}

Randomised, placebo-controlled clinical trials of acupuncture are recommended for the evaluation of its efficacy with the goal of separating the specific effects from the non-specific ones. However, it is difficult to define acupuncture control [102]. Experimental and clinical studies have shown that minimal acupuncture, used as placebo control, is not necessarily inert from a physiological perspective. The relevance of using minimal acupuncture as placebo acupuncture must therefore be questioned $[103,104]$. Instead of reducing bias, this trial design may introduce a bias against the treatment being tested [5]. Therefore, the results obtained from this method should be interpreted with care, particularly under the conditions that minimal acupuncture may have both specific and non-specific effects [105]. 


\section{Competing interests}

The authors declare that they have no competing interests.

\section{Authors' contributions}

TL drafted the manuscript for discussion. JN and IL contributed their views and revised the manuscript. IL integrated all views and finalised the manuscript. All authors read and approved the final version of the manuscript.

\section{References}

I. Walach $\mathrm{H}$ : The efficacy paradox in randomized controlled trials of CAM and elsewhere: beware of the placebo trap. J Alt Compl Med 200I, 7:213-218.

2. Devereaux PJ, Yusuf S: The evolution of the randomized controlled trial and its role in evidence-based decision making. J Intern Med 2003, 254: I05-II3.

3. Andersson S, Lundeberg T: Acupuncture - from empiricism to science: functional background to acupuncture effects in pain and disease. Med Hypotheses 1995, 45:27|-281.

4. Paterson C, Dieppe P: Characteristic and incidental (placebo) effects in complex interventions such as acupuncture. $B M]$ 2005, 330: 1202-1205.

5. Birch S: A review and analysis of placebo treatments, placebo effects, and placebo controls in trials of medical procedures when sham is not inert. J Alt Complt Med 2006, I 2:303-3 I0.

6. Cummings M: Research shorts. Acupunct Med 2006, 24:188-189.

7. Lund I, Lundeberg T: Are minimal, superficial or sham acupuncture procedures acceptable as inert placebo controls? Acupunct Med 2006, 24: I3-I5.

8. Kerr CE, Milne I, Kaptchuk T]: William Cullen and a missing mind-body link in the early history of placebos. J $R$ Soc Med 2008, I $01: 89-92$.

9. Enck P, Benedetti F, Schedlowsk M: New insights into the placebo and nocebo responses. Neuron 2008, 59:195-206.

10. Dincer F, Linde K: Sham interventions in randomized clinical trials of acupuncture - a review. Complement Ther Med 2003, I I:235-242.

II. Lundeberg T, Lund I: Are reviews based on sham acupuncture procedures in fibromyalgia syndrome (FMS) valid? Acupunct Med 2007, 25:100-106.

12. Activation of the somatosensory cortex during A-beta-fiber mediated hyperalgesia. A MSI study. Brain Res 2000, 87 I ( I):75-82.

13. Baldry P: Large tender areas, not discrete points, observed in patients with fibromyalgia. Acupunct Med 2007, 25:203.

14. Baliki MN, Geha PY, Apkarian AV, Chialvo DR: Beyond feeling: chronic pain hurts the brain, disrupting the default-mode network dynamics. J Neurosci 2008, 28:| 398-| 403.

15. Seifert F, Maihöfner C: Central mechanisms of experimental and chronic neuropathic pain: Findings from functional imaging studies. Cell Mol Life Sci 2008 in press.

16. Apkarian AV, Baliki MN, Geha PY: Towards a theory of chronic pain. Prog Neurobiol 2008 in press.

17. Dhond RP, Yeh C, Park K, Kettner N, Napadow V: Acupuncture modulates resting state connectivity in default and sensorimotor brain networks. Pain 2008, 136:407-418.

18. Nielsen LA, Henriksson KG: Pathophysiological mechanisms in chronic musculoskeletal pain (fibromyalgia): the role of central and peripheral sensitization and pain disinhibition. Best Pract Res Clin Rheumatol 2007, 2 I:465-480.

19. White A, Cummings M, Barlas P, Cardini F, Filshie J, Foster NE, Lundeberg T, Stener-Victorin E, Witt C: Defining an adequate dose of acupuncture using a neurophysiological approach - a narrative review of the literature. Acupunct Med 2008, 26: I | |- I 20.

20. Thomas M, Lundeberg T: Does acupuncture work? Pain Clinical Updates 1996, IV:I-II.

2I. Lund I, Lundeberg T: Aspects of pain, its assessment and evaluation from an acupuncture perspective. Acupunct Med 2006, 24:109-117.

22. Lundeberg T, Lund I: Did 'The Princess on the Pea' suffer from fibromyalgia syndrome? The influence on sleep and the effects of acupuncture. Acupunct Med 2007, 25: 184-197.
23. Robinson N: Integrated traditional Chinese medicine. Complement Ther Clin Pract 2006, I 2: I 32-140.

24. Yu F, Takahashi T, Moriya J, Kawaura K, Yamakawa J, Kusaka K, Itoh T, Morimoto S, Yamaguchi N, Kanda T: Traditional Chinese medicine and Kampo: a review from the distant past for the future. J Int Med Res 2006, 34:23 I-239.

25. Foster NE, Thomas E, Barlas P, Hill JC, Young J, Mason E, Hay EM: Acupuncture as an adjunct to exercise based physiotherapy for osteoarthritis of the knee: randomized controlled trial. BMJ 2007, 335:436.

26. Vas J, Ortega C, Olmo V, Perez-Fernandez F, Hernandez L, Medina I, Seminario JM, Herrera A, Luna F, Perea-Milla E, Mendez C, Madrazo F, Jimenez C, Ruiz MA, Aguilar I: Single-point acupuncture and physiotherapy for the treatment of painful shoulder: a multicentre randomized controlled trial. Rheumatolog 2008, 47:887-993

27. Nordin M: Low-threshold mechanoreceptive and nociceptive units with unmyelinated fibres in the human supraorbital nerve. J Physiol 1990, 426:229-240.

28. Campbell $A$ : The limbic system and emotion in relation to acupuncture. Acupunct Med 1999, I7:124.

29. Johansen-Berg H, Christensen V, Woolrich M, Matthews PM: Attention to touch modulates activity in both primary and secondary somatosensory areas. Neuroreport 2000, I I:|237-I24 I.

30. Olausson H, Lamarre Y, Backlund H, Morin C, Wallin BG, Starck G, Ekholm S, Strigo I, Worsley K, Vallbo AB, Bushnell MC: Unmyelinated tactile afferents signal touch and project to insular cortex. Nat Neurosci 2002, 5:900-904.

31. Wessberg J, Olausson H, Fernstrom KW, Vallbo $A B$ : Receptive field properties of unmyelinated tactile afferents in the human skin. J Neurophysiol 2003, 89:| 567-I575.

32. Cole J, Bushnell MC, McGlone F, Elam M, Lamarre Y, Vallbo A, Olausson $\mathrm{H}$ : Unmyelinated tactile afferents underpin detection of low-force monofilaments. Muscle Nerve 2006, 34: I05-107.

33. Wang SM, Kain ZN, White P: Acupuncture analgesia: I: The scientific basis. Anesth Analg 2008, 106:602-610.

34. Okada K, Kawakita K: Analgesic Action of Acupuncture and Moxibustion: A Review of Unique Approaches in Japan. Evid Based Complement Alternat Med 2007 in press.

35. Lin JG, Chen WL: Acupuncture analgesia: a review of its mechanisms of actions. Am J Chin Med 2008, 36:635-645.

36. Zhao ZQ: Neural mechanisms underlying acupuncture analgesia. Prog Neurobiol 2008, 85:335-375.

37. Han JS: Acupuncture and endorphins. Neurosci Lett 2004, $361: 258-261$.

38. Chae Y, Kim SY, Park HS, Lee H, Park HJ: Experimentally manipulating perceptions regarding acupuncture elicits different responses to the identical acupuncture stimulation. Physiol Behav 2008, 95:515-520.

39. Mao J, Armstrong K, Farrar JT, Bowman MA: Acupuncture expectancy scale: development and preliminary validation in China. Explore (NY) 2007, 3:372-377.

40. Harris RE, Gracely RH, McLean SA, Williams DA, Giesecke T, Petzke F, Sen A, Clauw DJ: Comparison of clinical and evoked pain measures in fibromyalgia. J Pain 2006, 7:521-527.

41. Kong J, Gollub RL, Rosman IS, Webb JM, Vangel MG, Kirsch I, Kaptchuk TJ: Brain activity associated with expectancyenhanced placebo analgesia as measured by functional magnetic resonance imaging. J Neurosci 2006, 26:38|-388.

42. Pariente J, White P, Frackowiak RS, Lewith G: Expectancy and belief modulate the neuronal substrates of pain treated by acupuncture. Neuroimage 2005, 25: | |6I-I I67.

43. Bausell RB, Lao L, Bergman S, Lee WL, Berman BM: Is acupuncture analgesia an expectancy effect? Preliminary evidence based on participants' perceived assignments in two placebo-controlled trials. Eval Health Prof 2005, 28:9-26.

44. Lundeberg T, Lund I, Näslund J: Acupuncture-self-appraisal and the reward system. Acupunct Med 2007, 25:87-99.

45. Clark L, Sahakian B]: Cognitive neuroscience and brain imaging in bipolar disorder. Dialogues Clin Neurosci 2008, I0:153-163.

46. Reagan LP, Grillo CA, Piroli GG: The As and Ds of stress: metabolic, morphological and behavioral consequences. Eur J Pharmacol 2008, 585:64-75.

47. Aleman A, Swart M, van Rijn S: Brain imaging, genetics and emotion. Biol Psychol 2008, 79:58-69. 
48. Clark MS, Bond MJ, Hecker JR: Environmental stress, psychological stress and allostatic load. Psychol Health Med 2007, I 2: 18-30.

49. Deng G, Hou BL, Holodny Al, Cassileth BR: Functional magnetic resonance imaging ( $\mathrm{FMRI}$ ) changes and saliva production associated with acupuncture at LI-2 acupuncture point: a randomized controlled study. BMC Complement Altern Med 2008 , 8:37.

50. Fang J, Jin Z, Wang Y, Li K, Kong J, Nixon EE, Zeng Y, Ren Y, Tong H, Wang $Y$, Wang $P$, Hui KK: The salient characteristics of the central effects of acupuncture needling: Limbic-paralimbic-neocortical network modulation. Hum Brain Mapp 2008 in press.

5I. Ho SC, Chiu JH, Yeh TC, Hsieh JC, Cheng HC, Cheng H, Ho LT: Quantification of electroacupuncture-induced neural activity by analysis of functional neural imaging with monocrystalline iron oxide nanocolloid enhancement. Am J Chin Med 2008, 36:493-504

52. Wu MT, Sheen JM, Chuang KH, Yang P, Chin SL, Tsai CY, Chen CJ, Liao JR, Lai PH, Chu KA, Pan HB, Yang CF: Neuronal specificity of acupuncture response: a fMRI study with electroacupuncture. Neuroimage 2002, 16:1028-1037.

53. Wu MT, Hsieh JC, Xiong J, Yang CF, Pan HB, Chen YC, Tsai G, Rosen $\mathrm{BR}$, Kwong KK: Central nervous pathway for acupuncture stimulation: localization of processing with functional MR imaging of the brain-preliminary experience. Radiology 1999, 212:133-|4|.

54. Napadow V, Kettner N, Liu J, Li M, Kwong KK, Vangel M, Makris N, Audette J, Hui KK: Hypothalamus and amygdala response to acupuncture stimuli in Carpal Tunnel Syndrome. Pain 2007, 130:254-266.

55. Kaptchuk TJ, Stason WB, Davis RB, Legedza AR, Schnyer RN, Kerr CE, Stone DA, Nam BH, Kirsch I, Goldman RH: Sham device v inert pill: randomised controlled trial of two placebo treatments. BMJ 2006, 332:391-397.

56. Diener HC, Matias-Guiu J, Hartung E, Pfaffenrath V, Ludin HP, Nappi $G$, De Beukelaar F: Efficacy and tolerability in migraine prophylaxis of flunarizine in reduced doses: a comparison with propranolol 160 mg daily. Cephalalgia 2002, 22:209-22I.

57. Kuy PH van der, Lohman JJ: A quantification of the placebo response in migraine prophylaxis. Cephalalgia 2002, 22:265-270.

58. Linde K, Streng A, Jürgens S, Hoppe A, Brinkhaus B, Witt C, Wagenpfeil S, Pfaffenrath V, Hammes MG, Weidenhammer W, Willich SN, Melchart D: Acupuncture for patients with migraine: a randomized controlled trial. JAMA 2005, 293:2। I8-2I 25.

59. Diener HC, Kronfeld K, Boewing G, Lungenhausen M, Maier C, Molsberger A, Tegenthoff $M$, Trampisch HJ, Zenz M, Meinert R, GERAC Migraine Study Group: Efficacy of acupuncture for the prophylaxis of migraine: a multicentre randomised controlled clinical trial. Lancet Neurol 2006, 5:3 I0-3I6.

60. Streng A, Linde K, Hoppe A, Pfaffenrath V, Hammes M, Wagenpfeil S, Weidenhammer W, Melchart D: Effectiveness and tolerability of acupuncture compared with metoprolol in migraine prophylaxis. Headache 2006, 46: I492-1502.

61. Brinkhaus B, Witt CM, Jena S, Linde K, Streng A, Wagenpfeil S, Irnich $D$, Walther HU, Melchart D, Willich SN: Acupuncture in patients with chronic low back pain - a randomised controlled trial. Arch Intern Med 2006, 166:450-457.

62. Witt CM, Jena S, Selim D, Brinkhaus B, Reinhold T, Wruck K, Liecker B, Linde K, Weqscheider K, Willich SN: Pragmatic randomized trial evaluating the clinical and economic effectiveness of acupuncture for chronic low back pain. Am J Epidemiol 2006, 1 64:487-496.

63. Haake $M$, Müller HH, Schade-Brittinger C, Basler HD, Schäfer $H$, Maier C, Endres HG, Trampisch HJ, Molsberger A: German Acupuncture Trials (GERAC) for chronic low back pain: randomized, multicenter, blinded, parallel-group trial with 3 groups. Arch Intern Med 2007, 167:1892-1898. Erratum in: Arch Intern Med 2007, 167:2072.

64. Witt C, Brinkhaus B, Jena S, Linde K, Streng A, Wagenpfeil S, Hummelsberger ], Walther HU, Melchart D, Willich SN: Acupuncture in patients with osteoarthritis of the knee $-\mathbf{a}$ randomized trial. Lancet 2005, 366:136-143.

65. Scharf HP, Mansmann U, Streitberger K, Witte S, Krämer J, Maier C, Trampisch HJ, Victor N: Acupuncture and knee osteoarthritis: a three-armed randomized trial. Ann Intern Med 2006 , 145:12-20.
66. Witt CM, Jena S, Brinkhaus B, Liecker B, Wegscheider K, Willich SN: Acupuncture in patients with osteoarthritis of the knee or hip. A randomized, controlled trial with an additional nonrandomized arm. Arthritis Rheum 2006, 54:3485-3493.

67. Richtlinie Methoden vertragsärztliche Versorgung (Akupunktur/siehe Beschluss vom I 9.09.2006) [http://www.g-ba.de/ informationen/beschluesse/295/]

68. Dhond RP, Kettner N, Napadow V: Do the neural correlates of acupuncture and placebo effects differ? Pain 2007, I 28:8-I2.

69. Napadow V, Kettner N, Liu J, Li M, Kwong KK, Vangel M, Makris N, Audette J, Hui KK: Hypothalamus and amygdala response to acupuncture stimuli in carpal tunnel syndrome. Pain 2007 , I 30:254-266

70. Napadow V, Liu J, Li M, Kettner N, Ryan A, Kwong KK, Hui KK, Audette JF: Somatosensory cortical plasticity in carpal tunnel syndrome treated by acupuncture. Hum Brain Map 2007, 28: $159-17 \mid$.

7I. MacPherson H, Green G, Nevado A, Lythgoe MF, Lewith G, Devlin R, Haselfoot R, Asghar AU: Brain imaging of acupuncture: comparing superficial with deep needling. Neurosci Lett 2008 , 434:144-149.

72. Poznanski A, Hsu M, Gracely R, Daniel C, Harris R: Differences in central neural pain processing following acupuncture and sham acupuncture therapy in fibromyalgia (FM). American Pain Society's 27th Annual Scientific Meeting: 8-10 May 2008 :Abstract: 8290.

73. Qin W, Tian J, Bai L, Pan X, Yang L, Chen P, Dai J, Ai L, Zhao B, Gong Q, Wang W, von Deneen KM, Liu Y: FMRI Connectivity Analysis of Acupuncture Effects on an Amygdala-Associated Brain Network. Mol Pain 2008, 4:55.

74. Bai L, Tian J, Qin W, Pan X, Yang L, Chen P, Chen H, Dai J, Ai L, Zhao $B$ : Exploratory analysis of functional connectivity network in acupuncture study by a graph theory mode. Conf Proc IEEE Eng Med Biol Soc 2007:2023-2026.

75. Fang J, Jin Z, Wang Y, Li K, Kong J, Nixon EE, Zeng Y, Ren Y, Tong H, Wang $Y$, Wang $P$, Hui KK: The salient characteristics of the central effects of acupuncture needling: Limbic-paralimbic neocortical network modulation. Hum Brain Mapp 2008 in press.

76. Qin W, Tian J, Pan X, Yang L, Zhen Z: The correlated network of acupuncture effect: a functional connectivity study. Conf Proc IEEE Eng Med Biol Soc 2006, I:480-3.

77. Hui KK, Liu J, Makris N, Gollub RL, Chen AJ, Moore Cl, Kennedy DN, Rosen BR, Kwong KK: Acupuncture modulates the limbic system and subcortical gray structures of the human brain: evidence from fMRI studies in normal subjects. Hum Brain Mapp 2000, 9:। 3-25.

78. Yoo SS, Teh EK, Blinder RA, Jolesz FA: Modulation of cerebellar activities by acupuncture stimulation: evidence from fMR study. Neuroimage 2004, 22:932-940.

79. Macdonald AJ, Macrae KD, Master BR, Rubin AP: Superficial acupuncture in the relief of chronic low back pain. Ann $R$ Coll Surg Engl 1983, 65:44-46.

80. Thomas M, Eriksson SV, Lundeberg T: A comparative study of diazepam and acupuncture in patients with osteoarthritis pain: a placebo controlled study. Am J Chin Med I991, I 9:95-100.

81. Näslund I, Näslund UB, Odenbring S, Lundeberg T: Sensory stimulation (acupuncture) for the treatment of idiopathic anterior knee pain. J Rehab Med 2002, 34:23 I-238.

82. Kaptchuk T], Kelley JM, Conboy LA, Davis RB, Kerr CE, Jacobson EE, Kirsch I, Schyner RN, Nam BH, Nguyen LT, Park M, Rivers AL, McManus C, Kokkotou E, Drossman DA, Goldman P, Lembo Al: Components of placebo effect: randomised controlled trial in patients with irritable bowel syndrome. BMJ 2008, 336:999-1003.

83. Weidenhammer W, Linde K, Streng A, Hoppe A, Melchart D: Acupuncture for chronic low back pain in routine care. A multicenter observational study. Clin I Pain 2007, 23: I 28- I 35.

84. Wayne PM, Kerr CE, Schnyer RN, Legedza AT, Savetsky-German J, Shields MH, Buring JE, Davis RB, Conboy LA, Highfield E, Parton B, Thomas $P$, Laufer MR: Japanese-Style acupuncture for endometriosis-related pelvic pain in adolescents and young women: results of a randomized sham-controlled trial. I Pediatr Adolesc Gynecol 2008, 2 I :247-257.

85. Scott DJ, Stohler CS, Egnatuk CM, Wang H, Koeppe RA, Zubieta JK: Individual differences in reward responding explain placeboinduced expectations and effects. Neuron 2007, 55:325-336. 
86. Faria $\mathrm{V}$, Fredrikson M, Furmark T: Imaging the placebo response: a neurofunctional review. Eur Neuropsychopharmacol 2008, 18:473-485.

87. Cameron OG: Interoception: the inside story - a model for psychosomatic processes. Psychosom Med 2001, 63:697-7I0.

88. Lane RD: Neural substrates of implicit and explicit emotional processes: a unifying framework for psychosomatic medicine. Psychosom Med 2008, 70:214-231.

89. Holland PC: Cognitive versus stimulus-response theories of learning. Learn Behav 2008, 36:227-24I.

90. Colloca L, Tinazzi M, Recchia S, Le Pera D, Fiaschi A, Benedetti F, Valeriani $M$ : Learning potentiates neurophysiological and behavioral placebo analgesic responses. Pain 2008, 139:306-14.

91. Rabinak CA, Zimmerman JM, Chang CH, Orsini CA: Bidirectional changes in the intrinsic excitability of infralimbic neurons reflect a possible regulatory role in the acquisition and extinction of Pavlovian conditioned fear. J Neurosci 2008 , 28:7245-7247.

92. Renger JJ: Overview of experimental and conventional pharmacological approaches in the treatment of sleep and wake disorders. Curr Top Med Chem 2008, 8:937-953.

93. MacPherson $H$, Thomas K: Self-help advice as a process integral to traditional acupuncture care: implications for trial design. Complement Ther Med 2008, 16:101-106.

94. MacPherson H, Thorpe L, Thomas K: Beyond needling-therapeutic processes in acupuncture care: a qualitative study nested within a low-back pain trial. J Altern Complement Med 2006, I 2:873-880

95. Liu T: Role of acupuncturist in acupuncture treatment. Evid Based Complement Alternat Med 2007, 4:3-6.

96. Hunnicutt SE, Grady J, McNearney TA: Complementary and alternative medicine use was associated with higher perceived physical and mental functioning in early systemic sclerosis. Explore (NY) 2008, 4:259-263.

97. Liu T: Acupuncture: What underlies needle administration? Evid Based Complement Alternat Med 2008 in press.

98. Jena S, Witt CM, Brinkhaus B, Wegscheider K, Willich SN: Acupuncture in patients with headache. Cephalalgia 2008, 28:969-979.

99. Linde K, Streng A, Hoppe A, Weidenhammera W, Wagenpfeil S, Melchart D: Randomized trial vs observational study of acupuncture for migraine found that patient characteristics differed but outcomes were similar. J Clin Epidemiol 2007, 60:280-287.

100. Paterson C, Zheng Z, Xue C, Wang Y: Playing their parts": the experiences of participants in a randomized sham-controlled acupuncture trial. J Altern Complement Med 2008, 14:199-208.

10I. Linde K, Dincer F: How informed is consent in sham-controlled trials of acupuncture? J Altern Complement Med 2004, 1 0:379-385.

102. Lundeberg T, Hurtig T, Lundeberg S, Thomas M: Long-term results of acupuncture in chronic head and neck pain. Pain Clinic 1988, 2:15-31.

103. Campbell A: Point specificity of acupuncture in the light of recent clinical and imaging studies. Acupunct Med 2006, 24:118-122.

104. Tsukayama H, Yamashita H, Kimura T, Otsuki K: Factors that influence the applicability of sham needle in acupuncture trials: two randomized, single-blind, crossover trials with acupuncture-experienced subjects. Clin J Pain 2006, 22:346-349.

105. Streitberger K, Kleihenz J: Introducing a placebo needle into acupuncture research. Lancet 1998, 352:364-365.
Publish with Bio Med Central and every scientist can read your work free of charge

"BioMed Central will be the most significant development for disseminating the results of biomedical research in our lifetime. "

Sir Paul Nurse, Cancer Research UK

Your research papers will be:

- available free of charge to the entire biomedical community

- peer reviewed and published immediately upon acceptance

- cited in PubMed and archived on PubMed Central

- yours - you keep the copyright
BioMedcentral 